\title{
Notes on the vocalizations of Social Flycatcher (Myiozetetes similis)
}

Peter Boesman

In the following we briefly analyze and compare voice of the different races of Social Flycatcher (Myiozetetes similis). We also try to quantify the extent of any vocal differences using the criteria proposed by Tobias et al. (2010), as a support for taxonomic review. We have made use of sound recordings available on-line from Xeno Canto $(\mathrm{XC})$ and Macaulay Library (ML).

Dawn songs are not available for all regions, therefore we give first an overview of the most common day-time vocalizations per region:

Northern Central American group (primulus, hesperis, texensis)
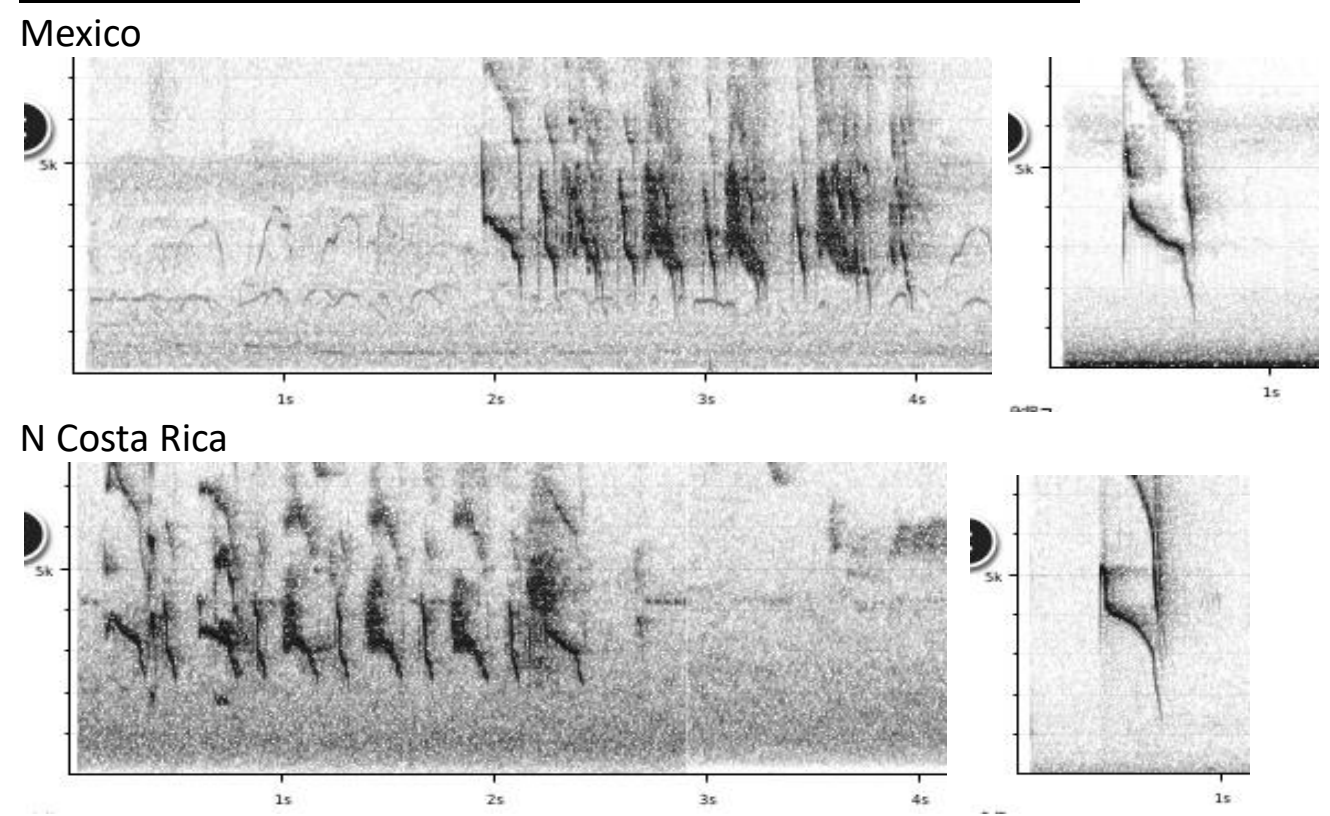

Pacific group (grandis)

W Ecuador
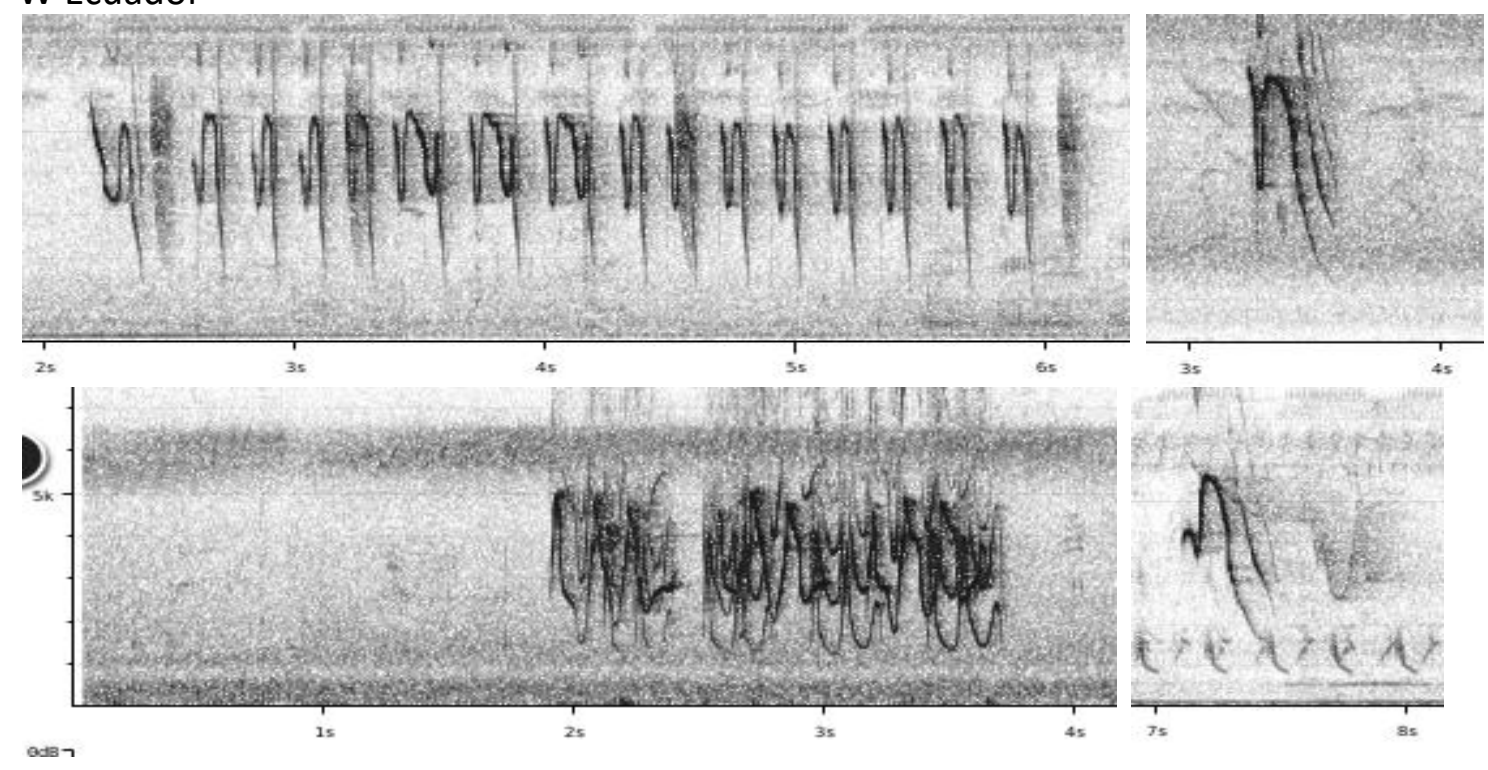


\section{HANDBOOK OF THE \\ BIRDS PF/THE WORLD}

\section{ORNITHOLOGICAL NOTES}

$\underline{\text { S Costa Rica, Panama, N Colombian/N Venezuelan group (colombianus) }}$
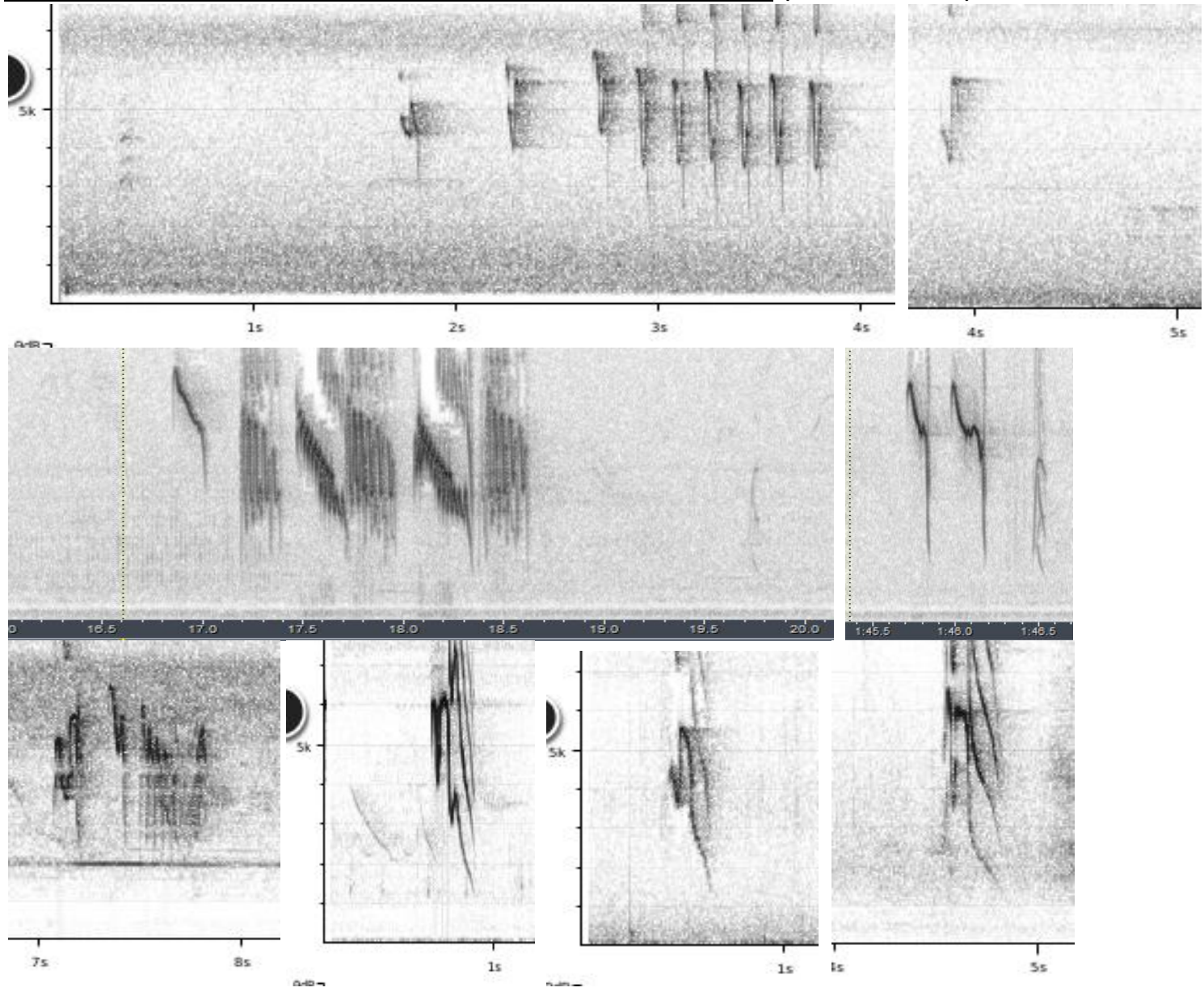

W Amazonian group (E Colombia, E Ecuador, E Peru, N Bolivia)
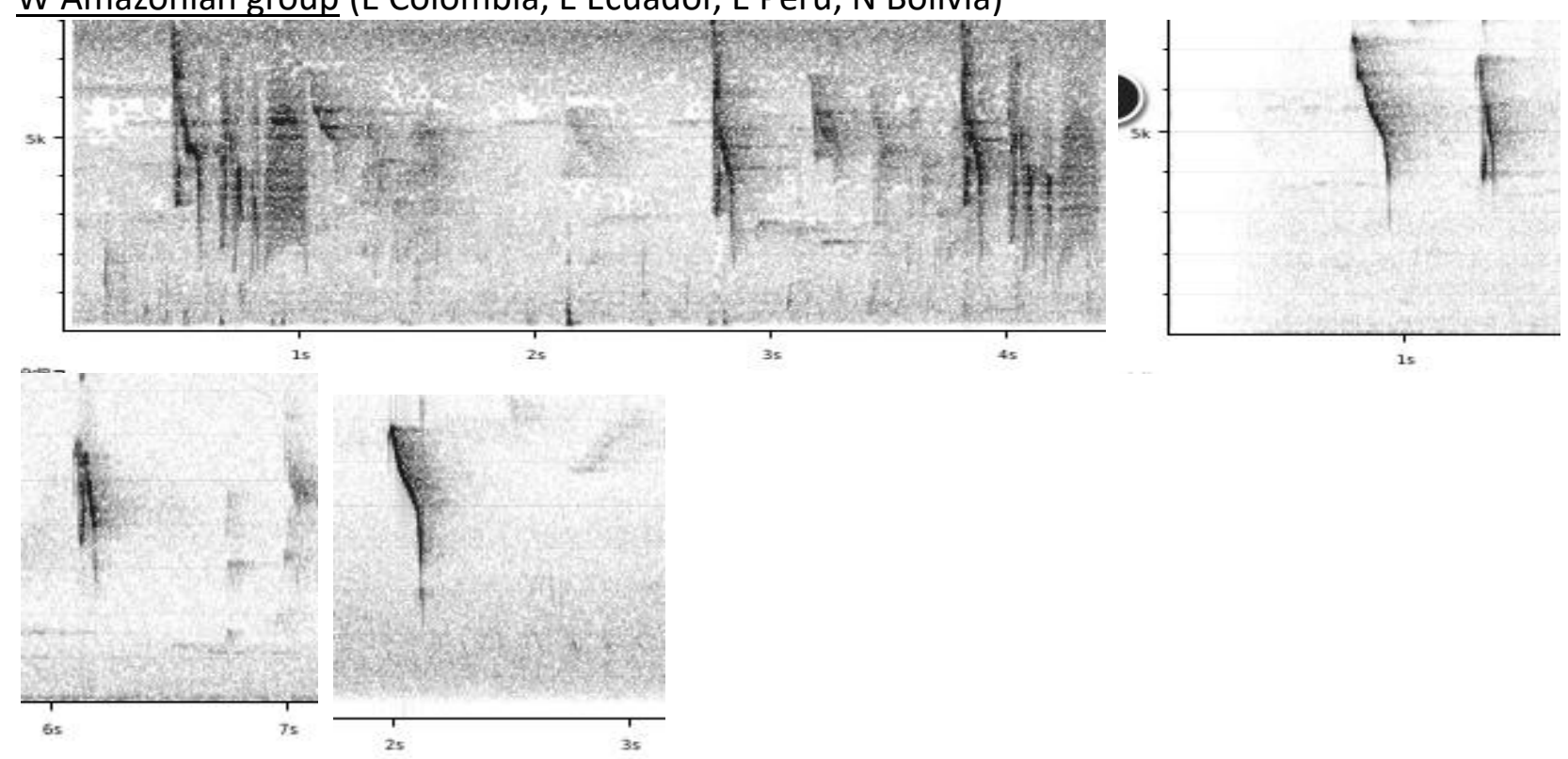


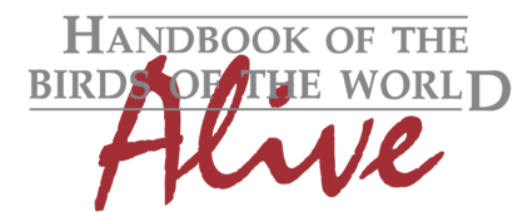

\section{ORNITHOLOGICAL NOTES}
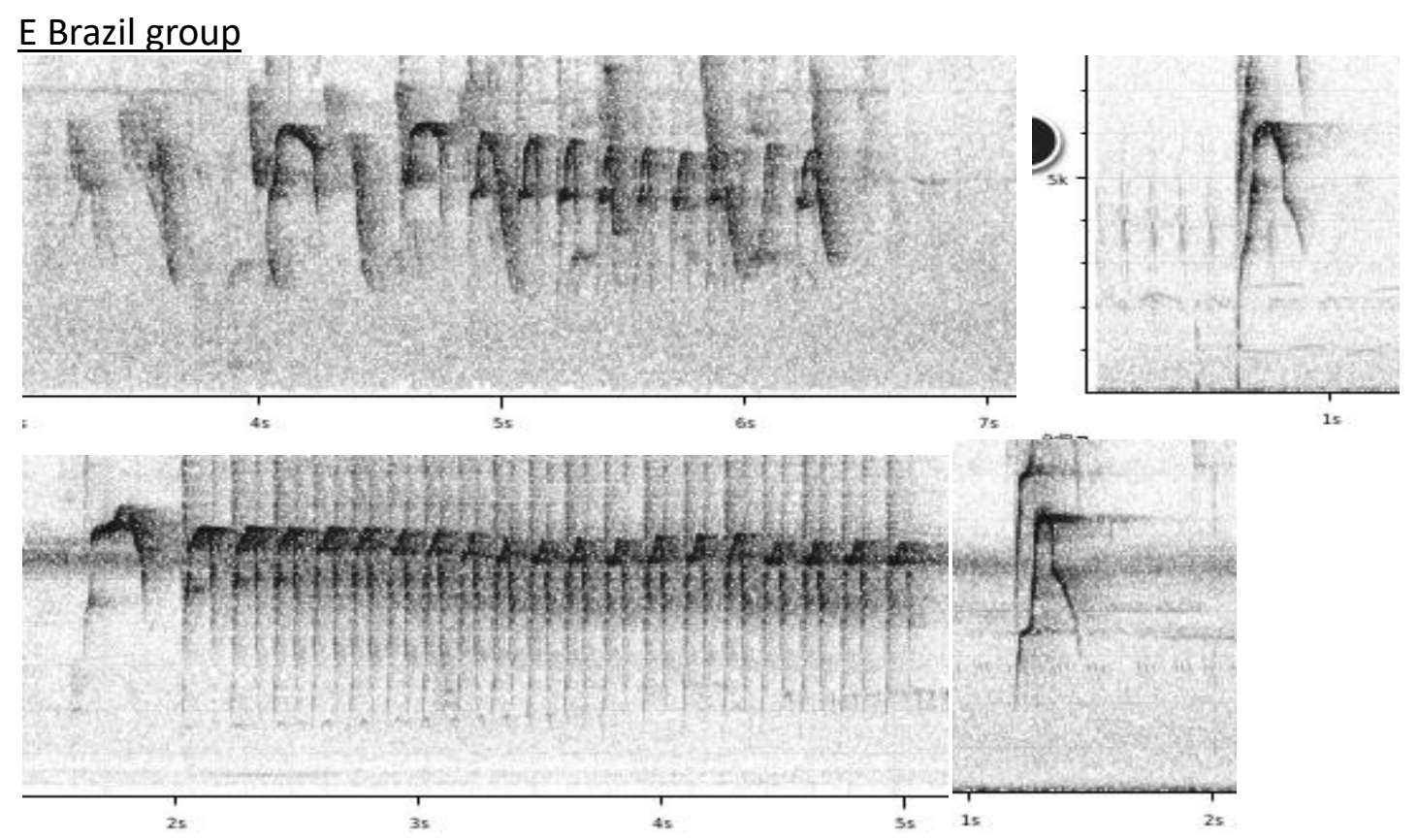

From the above overview, it is quite clear that voice differs substantially over its entire range. There is a clear similarity in voice between grandis and colombianus.

Based on voice, a logical grouping would be:

Group 1: M. s. primulus, M. s. hesperis, M. s. texensis

Group 2: M. s. columbianus, M. s. grandis

Group 3: M. s. similis

Group 4: M. s. pallidiventris

(we assume similis to be homogenous throughout its range, as there are surprisingly no recordings in XC beyond the West Amazonian region)

colombianus/grandis share some features with the northern Central American group, but common features of this enlarged group become then so weak vs the other groups, that such arrangement would not make much sense vocally.

At present, we only have a few dawn songs available:

Group 1: Mexico

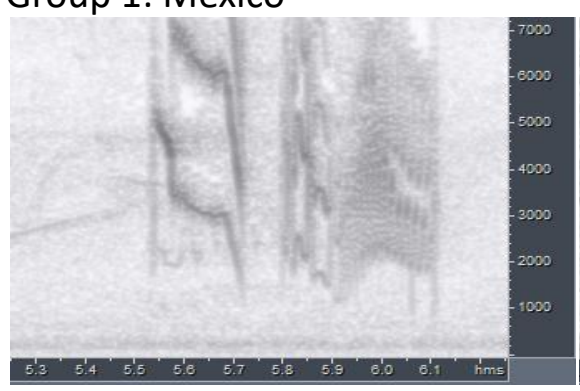

N Costa Rica

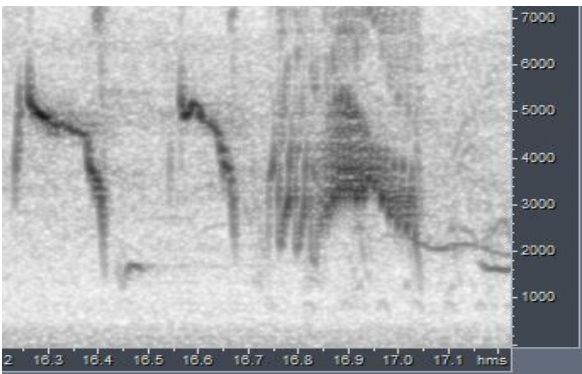



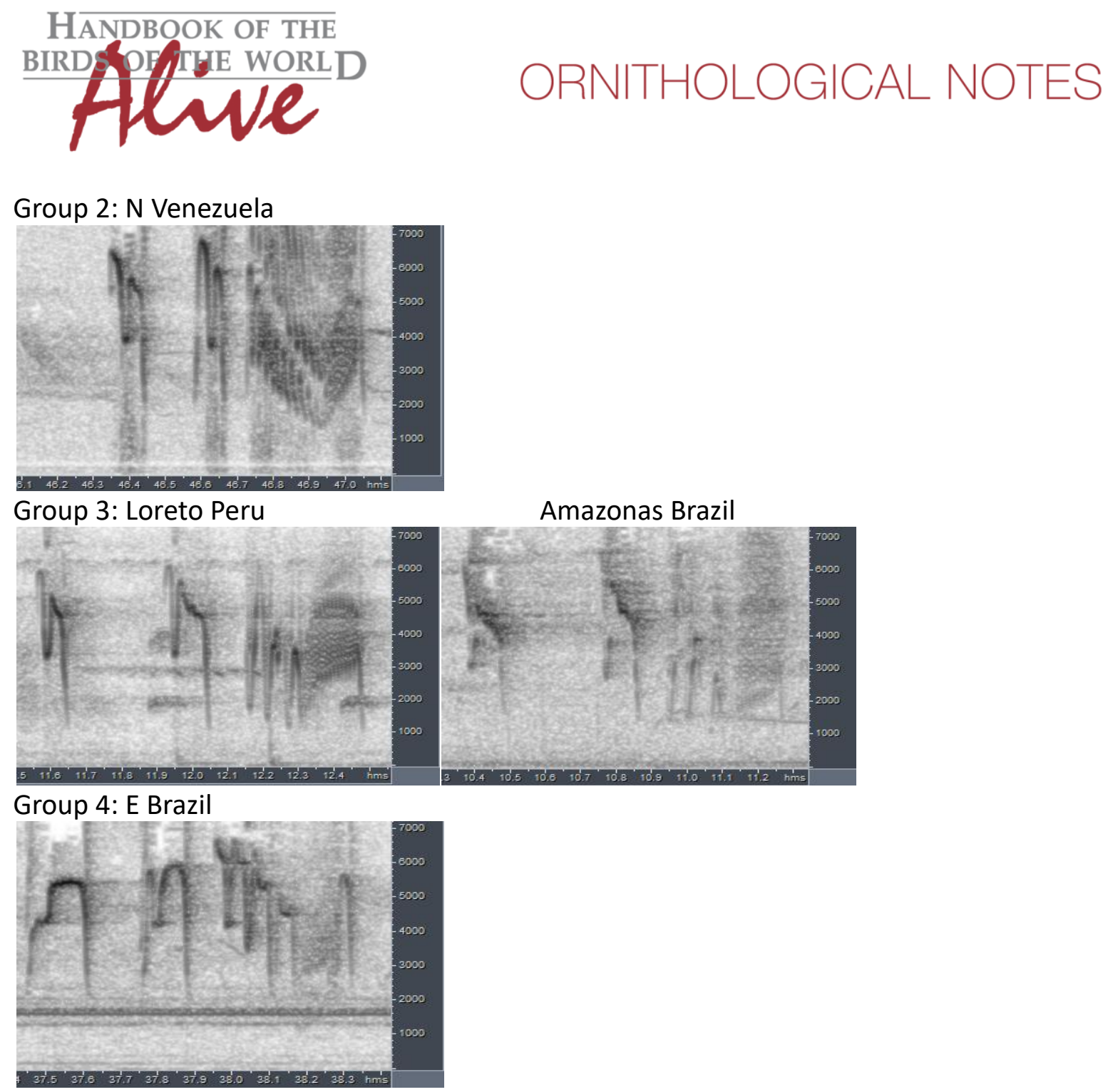

These are not very helpful in supporting the vocal grouping. At most, they seem to indicate that dawn song in Tyrannidae is not always the best indicator for speciation (cfr. several cases in Zimmerius and Myiarchus).

It is clear that only a thorough vocal analysis with more recordings of the entire vocabulary, including dawn songs for all groups, can bring more clarity in this complex case. And given that morphological differences in this genus are rather subtle at most, an in depth genetic analysis will undoubtedly be necessary to reach firm conclusions based on an integrative approach.

This note was finalized on 25th February 2016, using sound recordings available on-line at that moment. We would like to thank in particular the many sound recordists who placed their recordings for this species on XC and ML.

\section{References}

Tobias, J.A., Seddon, N., Spottiswoode, C.N., Pilgrim, J.D., Fishpool, L.D.C. \& Collar, N.J. (2010). Quantitative criteria for species delimitation. Ibis 152(4): 724-746. 


\section{Recommended citation}

Boesman, P. (2016). Notes on the vocalizations of Social Flycatcher (Myiozetetes similis). HBW Alive Ornithological Note 252. In: Handbook of the Birds of the World Alive. Lynx Edicions, Barcelona. (retrieved from http://www.hbw.com/node/932253 on 4 October 2016). 